\title{
Preventive Oncology in Geriatrics: The Need of the Hour
}

\section{Puri $\mathrm{S}^{1 *}$, Choudhary $\mathrm{K}^{2}$ and Pardeep $\mathrm{A}^{3}$}

${ }^{1}$ Assist Prof, Department of Community Medicine, Government Medical College and Hospital Sector 32, Chandigarh, India

${ }^{2}$ Demonstrator, Department of Community Medicine, Government Medical College and Hospital Sector 32, Chandigarh, India

${ }^{3} \mathrm{MBBS}$ Student, GMCH-32 .Chandigarh, India

\begin{abstract}
Cancer is a leading cause of morbidity and mortality both globally and also in India. Aging itself is a major risk factor for cancer. A wealth of literature endorses that early detection leads to prevention or cure from disability and improves quality of life. Preventive oncology, a multidisciplinary branch, incorporates the measures taken to prevent development of risk factors and disease progression to malignant phase owing to causal association with modifiable risk factors. It is validated in many studies that major barriers in early diagnosis and treatment of geriatric cancers are attributed to lack of awareness and stereotyping of aging, among others. This discipline should also be promoted in light of its huge impact on not only health but also on economy.
\end{abstract}

Keywords: Aging; Geriatrics; cancer; preventive oncology

\section{INTRODUCTION}

Cancer is the second leading cause of death worldwide and accounts for a share of $13 \%$ (8.7 millions) of total global deaths [1]. Noticeably, this number is very close to the industrialized world. Further the cancer mortality in India is projected to increase and touch the figure of nine lakh deaths by the end of this decade [2]. It has been recognized that the most significant risk factor for the development of cancer is aging. More than 12 to $23 \%$ of all the cancers are found to be present among adults who have lived 65 -years-of their lives [3]. Since only $5.4 \%$ Indians are 65 plus, this is a cause for great worry [4]. Further sexagenarians or older have 15 times greater risk of being caught by a cancer if they are males and 8 times if they are females [5] (Figure 1).

The demographic shift and the resultant increase in the number of elderly patients with cancer, which was predicted by the founders of geriatric oncology (Kennedy, Yanick and others) have now arrived! Kennedy had stated-"Care of older people needs to be part of medical education and oncology education. Research will help attain a desirable quality of life with aging and a reduced morbidity" $[6,7]$.

\section{MATERIALS AND METHODS}

Since there is a little research conducted whatsoever on preventive geriatrics in this part of the Indian subcontinent, the authors critically examined the various studies in the discipline over the last decade to come to some pertinent conclusion.

PubMed search of the published English literature was done, using the search terms 'elderly', 'cancer', 'preventive oncology and 'geriatrics including also manual searches on references in articles to these topics.

\section{Geriatric Preventive Oncology can be equated with screening?}

What everybody thinks of when it comes to geriatric preventive oncology is -Screening! Routine screenings are for a few of cancers only. Many studies have validated that the biggest and the first barrier in early diagnosis and treatment for cancers is lack of awareness/knowledge. Recommended clinical preventive services, such as counselling to prevent tobacco use and excessive alcohol consumption can considerably reduce the share of cancers by reducing exposure to these and other known agents causing cancers $[8,9]$. Only focusing on screenings could well be a red herring! According to Kietzman et al, linkages between communities and health care providers can reduce barriers to access or avail recommended screening tests and other clinical preventive services.

\section{Cancer Myths and Lack Of Awareness in Geriatrics}

Elderly should learn the right knowledge and attitude to

Correspondence to: Puri S, Assist Prof, Department of Community Medicine, Government Medical College and Hospital Sector 32, Chandigarh, India,Tel: 9646121657; E-mail: soniagpuri@gmail.com

Received: May 22, 2020, Accepted: June 05, 2020, Published: June 12, 2020

Citation: Puri S, Choudhary K, Pardeep A (2020) Preventive Oncology in Geriatrics: The Need of the Hour. J Gerontol Geriatr Res 9: 511. doi: $10.35248 / 2167-7182.20 .9 .511$

Copyright: (C) 2020 Puri S, et al. This is an open-access article distributed under the terms of the Creative Commons Attribution License, which permits unrestricted use, distribution, and reproduction in any medium, provided the original author and source are credited. 

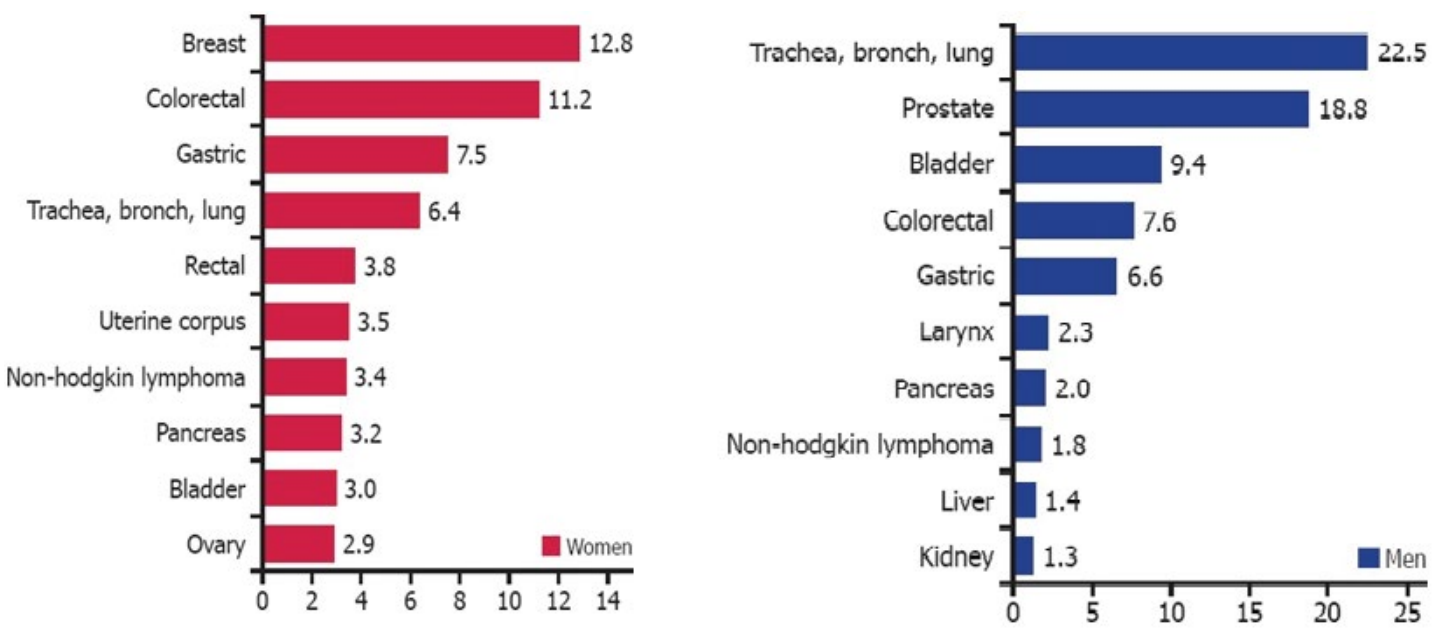

Figure 1: Distribution of some of the most frequently seen cancer types in elderly.

combat cancers [10]. According to Estape et al, older people have cancer related myths and experiences from the times when little information about cancer was available [11]. Their personal and family experiences are of fear, concealment and denial. Especially the experiences with someone in the terminal phases are exceptionally painful and full of suffering. People often retain these emotional memories and become immune and resistant to new information. Therefore, she concluded that a number of cures or changes regarding what cancer means today sometimes did not arrive as clearly as their own experiences of which they often give an assessment of the only truth. Her study highlighted that $72 \%$ of elderly were not aware of their greater risk of developing cancer. Regarding early detection, more than $1 / 4^{\text {th }}$ thought it was impossible. More than half of the respondents did not know of prostate specific antigen importance in early detection and 16\% did not know the same for mammography. On top of it, a chunk of people believed that cancer is actually a punishment from god to those who did something wrong in their previous lives, while others said cancer is contagious. Back home the scenario is no different, if not worse.

Dey et al in their national capital study, as late as in 2016, concluded that there was lack of awareness in women regarding breast cancer [12]. In Chandigarh, the union territory with the highest per capita income, more than half of the respondents in Puri et al study did not know that lump/mass to be the cardinal symptom of breast cancer [13]. Breast self-examination (BSE), was known by only $33 \%$ to be the main preventive measure. Further even among them, only $1 / 4^{\text {th }}$ knew the correct methodology of BSE. This is the current scenario of cancer burden in Indian cities, let alone rural areas. There are no encouraging findings down south either; where a study by Awasthy et al in Kerala found that nearly $1 / 3^{\text {rd }}$ women had not heard of cancers [14]. 83.7\% were unaware of tests for cervical cancer and $2 / 3^{\text {rd }}$ was not aware of breast cancer test. Although $29.7 \%$ were aware of BSE, only $20.6 \%$ ever practiced it and those who did were from nuclear families. $54 \%$ correctly pointed out breast and uterus to be the most common sites affected by cancer. Noticeably, women with less education and higher age have less awareness regarding common cancers and their screening tests.

Cancers are often associated with wrong beliefs due to its relation with death, pain and suffering, it has to do with aspects that are difficult to suddenly change. This phenomenon is especially true for older people. Taboos about the disease makes the elderly develop attitudes of resignation and denial [11]. This aversive attitude towards cancers is one of the chief overlooked reasons in preventive oncology. According to Rudd et al, elderly in order to avail the recommended health services and adopt the desirable behavior need to comprehend the health information [15]. Herein comes the sensitivity and acumen of the multi-disciplinary staff to come to their wave length and then empathetically make cumulative attempts to counsel. He also suggested addressing problems with literacy, numeracy to increase the accessibility of health information and improve the effectiveness of cancer preventive initiatives aimed at older adults.

One other overlooked barrier in geriatric oncology is stereotyping of aging. This stereotyping that health professionals and patients themselves have, can have many harmful impact on patients. For instance, in daily practice, the risk of concluding that a patient is too physiologically old for a treatment is kept in mind. Conversely, such observation is not made in a relatively young patient. Therefore, countering ageism needs to be taken seriously into consideration in clinical practice. Schroyen recommended training programs for health professionals with emphasis on the following points [16]:

1. Being careful with our vocabulary. (Avoiding Elder Speak).

2. Trying to include positive commentary on aging. (Positive Stereotypes).

3. It's very important for the well-being of the patient to take time to talk. During the conversation, one might talk about their grandchildren to evoke some good memories. (Intergenerational Reminiscence) or about important activities for them (Self Affirmation).

This ageism not only seeps into the attitudes of the health professionals but also into the patients' friends' and relatives' attitudes [17]. Meanwhile, old people also are too quick to label themselves as part of the elderly population. Thus any health concern or distress is quickly attributed to old age. Persuading the elderly who are experiencing physical problems, to immediately consult a doctor is difficult. Older people often do not recognize the usefulness of early detection or initiating healthy behavior because they consider that at their age, it's no longer worthwhile [11]. Hooker et al suggested that strategies to address attitudes towards aging and consequent age discrimination have the potential to enhance efforts to promote healthy behaviors and thereby reduce cancer risks for older adults [18].

WHO report on cancer 2020 has in its heart-"Setting priorities, 
investing wisely and providing care for all" importantly, this ALL would be incomplete unless the geriatric population is not only included but also put on priority [19].

\section{Preventive Oncology Promotion In Geriatrics- A right Investment}

Talking of investment, India has reported a total productivity loss of $0.36 \%$ of Gross Domestic Product due to cancer [20]. One of every 3 cancer patient spends about half of per capita annual household expenditure on cancer hospitalization. Almost all the households with cancer patients resort to distress means of healthcare financing [21]. Moreover, with the given population of the country there is requirement of 1200 radiotherapy machines, whereas only 400 machines are available at present for cancer. Besides most of the modern cancer treatment facilities are concentrated in private hospitals which are extremely expensive, e.g., a single course of radiotherapy in a private hospital costs around 1,17,000 rupees. Evidently this does not include expenses on further treatments like surgery, chemotherapy and supportive medicines. Clearly, allocating resources for preventive oncology would be the wisest investment ever [22].

\section{DISCUSSION AND CONCLUSION}

More than 70-years-ago, WHO had defined health as not merely absence of disease but rather "a state of complete physical, mental and social well-being". In that same spirit, 'The Gerontologist 'has defined cancer prevention at older ages as more than merely the avoidance of deaths from cancer. Cancer prevention aims to delay or prevent the onset of new cancer cases and most importantly the quality of life spans. The goal is more cancer free years for as many people as possible, including increasing the number of older adults all over the world.

India has already acquired the label of an aging nation, with the share of its people above 60-years burgeoning as we keep galloping our country towards development with each passing year. It's nothing but obvious that we have to keep geriatric health as our priority. Undoubtedly cancer risk increases exponentially with age. About $70 \%$ of the deaths caused by cancer occur in this stage. Thus keeping in mind that the most important risk factor for cancer is aging, preventive oncology's importance could not be underlined more. Understanding the health status of an old adult is just as important, if not more, as comprehension of tumor biology. There is no dearth of studies all pointing out to prevention of cancers in elderly as not only the most efficient way for cancer treatment but also the most incredibly cost effective. It's truly the need of the hour. The goals set by Yanick and Kennedy is yet to be fully achieved!

\section{Competing interests}

None declared.

\section{Acknowledgement}

We are thankful to Mr Pranav Puri, student of SGGSS Chandigarh, for helping in collection of research studies.

\section{REFERENCES}

1. https://www.who.int/gho/publications/world_health_ statistics/2015/en/
2. Rajpal S, Kumar A, Joe W. Economic burden of cancer in India: Evidence from cross-sectional nationally representative household survey, 2014. PLoS One. 2018;13(2):e0193320.

3. Sarkar A, Shahi U. Assessment of cancer care in Indian elderly cancer patients. A single center study. South Asian J Cancer. 2013;2(4):202-208

4. Patil VM, Chakraborty S, Dessai S, Kumar SS, Ratheesan K, Bindu $\mathrm{T}$, et al. Patterns of care in geriatric cancer patients-An audit from a rural based hospital cancer registry in kerala. Indian J cancer. 2015;52 (1):157-161.

5. Yeole BB, Kurkure AP, Koyande SS. Geriatric cancers in India: An epidemiological and demographic review. Asian Pac J Cancer Prev. 2008;9(7):271-274.

6. Litchman SM, Hurria A, Jacobson PB. Geriatric oncology: An overview. J Clin Oncol. 2014;32(24):2521-2522.

7. Kennedy BJ. Aging and cancer. J ClinOncol. 1988;6(12):1903-1911.

8. Cinar D, Tas D. Cancer in the elderly. North Clin Istanb. 2015;2(1):73-80.

9. White MC, Holman DM, Goodman RA and Richardson LC. Cancer risk among older adults: Time for cancer prevention to go silver. Gerontologist. 2019;59(1):1-6.

10. Kietzman KG, Toy P, Bravo RL, Duru OK, Wallace SP. Multispectoral collaborations to increase use of recommended cancer screening and other clinical preventive services by older adults. Gerontologist. 2019;59(1):57-66.

11. Estape T. Cancer in the elderly: Challenges and barriers. Asia Pac J Oncol Nurs. 2018;5(1):40-42.

12. Dey S, Sharma S, Mishra A, Krishnan S, Govil J, Dhillon PK. Breast cancer awareness and prevention behavior among women of Delhi, India: Identifying barriers to early detection. Breast Cancer (Auckl). 2016; 10:146-156.

13. Puri S, Mangat C, Bhatia V, Kalia M, Sehgal A, Kaur A. Awareness of risk factors and aspects of breast cancer among north Indian women. The Internet J Health. 2008; 8(2):1-8.

14. Aswathy S, Sumithra S, Valsala LS, Sandheep S, Lohidas V, Shobha $\mathrm{P}$, et al. Self reported morbidity and awareness regarding common cancers in elderly women. J Commun Dis. 2006; 38(1):106-111.

15. Rudd RE. Health literacy considerations for new cancer prevention initiatives. Gerontologist. 2019; 59(1): 07-16.

16. Schroyen S, Adam S, Jerusalem G, Missotten P. Ageism and its clinical impact in Oncogeriatry: State of knowledge and therapeutic leads. Clin Interv Aging. 2014;10:117-125.

17. http://www.siog.org/files/public/estape.pdf

18. Hooker K, Mejia ST, Phibbs S, Tan E, Stevens J. Effects of age discrimination on self-perceptions of aging and cancer risk behaviors. Gerontologist. 2019;59(1): 28-37.

19. https://www.who.int/publications-detail/who-report-on-cancersetting-priorities-investing-wisely-and-providing-care-for-all

20. http://cancerindia.org.in/cancer-statistics/

21. Joe W. Distressed financing of out-of-pocket healthcare payments in India: Incidence and correlates. Health Policy and Planning. 2015; 30(6):728-741.

22. Marosi C, Koller M. Challenge of cancer in the elderly. ESMO Open. 2016;1:20 